\title{
Territorialismo e a política de desenvolvimento: estratégias de produção do território no Brasil
}

Territorialism and the development policy:
territory production strategies in Brazil

Weslley Cantelmo

Carlos Lobo

Ricardo Alexandrino Garcia

\begin{abstract}
Resumo
0 processo histórico-geográfico de formação da sociedade brasileira foi regido por promessas de modernidade, em que a noção de desenvolvimento, desdobrada da noção de progresso, foi o combustível social de sustentação do movimento de inserção das relações capitalistas no Brasil durante o século XX. A ideia prevalecente na ação governamental tem sido a superação da desigualdade regional por meio da inserção das regiões brasileiras no circuito competitivo capitalista. A proposta deste artigo é refletir sobre evidências de que esse discurso tem se sustentado como uma estratégia de produção de território, própria de agentes hegemônicos no circuito capitalista de reprodução. Para a compreensão desse processo, propõe-se o resgate de uma noção geográfica que tem sido posta à margem: o territorialismo.
\end{abstract}

Palavras-chave: território; territorialismo; estratégia; política; desenvolvimento.

\begin{abstract}
The historical-geographical formation process of the Brazilian society was conducted by modernity promises in which the notion of development, derived from the notion of progress, was the social fuel that sustained the movement of inclusion of capitalist relations in Brazil in the 20th century. The prevailing idea in governmental action has been the overcoming of regional inequality through the inclusion of Brazilian regions in the capitalism competitive circuit. This paper argues that this discourse has been a strategy of territory production, typical of hegemonic agents within the capitalist reproduction circuit. To understand this process, this paper revisits a geographical notion that has been forgotten: territorialism.
\end{abstract}

Keywords: territory; territorialism; strategy; policy; development 


\section{Introdução}

São variadas as incursões teóricas sobre a noção de territorialismo, realizadas por diferentes vertentes das ciências humanas e sociais. 0 próprio conceito de território, tão tradicional em determinadas disciplinas, como a Geografia, não escapa de definições sem maiores polêmicas, ainda que esteja atrelado diretamente às manifestações de poder. Costa (2006) chama atenção ao uso indiscriminado do conceito de territorialismo, às vezes associado a uma atitude politicamente agressiva e repressiva, expressa na não aceitação do "outro". Um bom exemplo da crítica de Costa (2006) refere-se à análise do economista político Arrighi (1996), que utiliza a ideia de territorialismo como explicativa da dinâmica de poder vigente nas sociedades pré-capitalistas (europeias, principalmente), cujo controle do território, como zona de controle da terra e da população, estabelece-se como principal elemento. Essa dinâmica de poder, na interpretação de Arrighi (1996), teria sido contraposta pela lógica de reprodução de poder da sociedade ocidental moderna. Costa (2006) questiona a falta de rigor de Arrighi no uso do conceito de território, que não raramente remete ao seu significado "mais comum": um "pedaço de chão". Quanto ao uso do termo territorialismo, a crítica se concentra na "má reputação" do conceito, que no âmbito dos estudos geográficos costuma fazer referência a um mau uso da territorialidade: práticas sociais que revelam intolerância com o "outro", com outras formas sociais ou culturais; uma espécie de terrorismo em favor de um território pretensamente único, naturalizado, a-histórico e "animalizado" (Costa, 2006; Brunet et al., 1993).
De fato, a crítica quanto ao uso do conceito de território em Arrighi reforça sua relevância. 0 próprio Costa (2006) aposta em sua capacidade como categoria de análise das relações sociais e, mais ainda, chama atenção às questões eminentemente ontológicas - de modo que o território deve ser considerado como um elemento inerente da sociabilidade humana. Contudo, baseando-se nas visões mais correntes da literatura geográfica, como demonstrado por Costa (2006), além dos argumentos expostos por Brunet et al. (1993), considera-se que o conceito de territorialismo pode assumir especial importância na análise das políticas de desenvolvimento adotadas na atualidade, principalmente se analisarmos os conflitos de sociabilidade que envolve tais políticas e, também, o próprio conceito de desenvolvimento.

Tendo como referência esse debate, 0 objetivo deste trabalho é apresentar e propor, à luz do conceito de territorialismo, um debate crítico sobre a compreensão de projetos de desenvolvimento, tão perseguidos e almejados, como estratégia de produção de territórios-mercadoria, que são expostos e negociados, tendo como seu principal promotor de vendas o próprio Estado, por meio de suas políticas públicas. Em contrapartida, novas e velhas territorialidades, descendentes da raiz social brasileira, são combatidas e tachadas de irracionais. Procura-se, dessa forma, explorar como a noção de territorialismo, usada para análise do desenvolvimento, reflete estratégias de poder que buscam renegar o "diferente". Quando se trata de desenvolvimento, o diferente é tudo aquilo que não se caracteriza como uma relação capitalista. Assim, uma questão central, quando se discute a produção de território no projeto desenvolvimentista de sociedade, 
enfrentam-se, na verdade, as práticas hegemônicas de poder na contemporaneidade, que são fundamentalmente as práticas capitalistas de (re)produção do espaço, em uma dinâmica que, na linguagem de Lefebvre (1991), está posto como práticas de dominação em contraposição à apropriação. Confirma-se, dessa forma, uma noção de territorialismo que representa um conjunto de relações que se baseiam em uma narrativa capitalista/desenvolvimentista e que, estrategicamente, se opõem a outras narrativas, em uma tentativa de autonaturalização e "animalização" de relações.

\section{0 territorialismo e o desenvolvimento: conceitos e discursos}

O debate sobre a noção de território tem no trabalho de Costa (2006) uma importante referência atual na literatura brasileira. ${ }^{1}$ Esse autor faz um minucioso levantamento das formulações conceituais sobre território e territorialidade, conforme cada contexto histórico específico. Costa (2006) demonstra que o conceito território, além de ser fundamental para a Geografia, também tem tradição em outras áreas do conhecimento com enfoques diferenciados, dentre as quais se destacam a Antropologia, a Economia, a Sociologia e a Ciência Política (Costa, 2006; Hissa, 2009). Uma característica central no debate sobre esse conceito diz respeito à dinâmica que envolve sua criação e desestruturação, tendo como fundamentos as elaborações de Deleuze e Guattari sobre o movimento de desterritorialização/reterritorialização. Costa (2006) procura desenvolver uma interpretação a respeito das diferentes concepções de território, tendo como base o binômio materialismo-idealismo, o qual se desdobra em função de duas outras perspectivas: uma visão parcial de território, que enfatiza separadamente uma determinada dimensão dentre as consideradas possíveis - natural, econômica, política e cultural; e uma perspectiva integradora do território, que tem como fundamento a integração das concepções fragmentadas, como resposta ampla às questões socioespaciais decorrentes das relações homem-natureza (Costa, 2006).

Essa leitura feita por Costa (2006) evidencia um olhar essencialmente ontológico sobre o território, dando ênfase às duas realidades que o compõem: a materialista e a ideológica. Dentro do campo das concepções materialistas, a vertente naturalista se destaca por apresentar, de maneira evidente, as relações entre homem e os outros seres e componentes da natureza e, obviamente, os conflitos aí postos. Contudo, destaca, também, o quanto 0 discurso da modernidade tende a separar homem e natureza e, portanto, separar suas perspectivas de território (Gonçalves, 2001; Costa, 2006). A geografia de Milton Santos também se destaca por revisar o conceito de território, em uma perspectiva materialista da relação entre economia e espaço. Esse autor faz uma rica análise sobre os "usos do território", em uma perspectiva ontológica, e enfatiza a força com que os processos econômicos o influenciam. Nesse sentido, não se trata de uma abordagem meramente economicista, mas de uma minuciosa e exaustiva busca dos determinantes sociais do território enquanto "usado" (Santos, 1996; Santos, 2005). Justamente essa característica, de "usado", própria do território, é que 
faz dele um híbrido, uma vez que, como objeto de uso, ele apresenta diversas faces. Nesse sentido, aqueles agentes sociais dotados de condições privilegiados usam o território como sua base de reprodução. Já, aos agentes sociais que não têm de meios de comando quanto a seu uso, resta a adaptação (Santos, 2000). Nesse sentido, o uso do território se dá em um contexto essencialmente relacional, em que se tem 0 ator e 0 agido que, por sua vez, também emprega um uso ao território, o de abrigo para a sua sobrevivência (Santos, 2000).

Essa leitura território é de extrema relevância para a compreensão do processo de desenvolvimento. As formas de uso do território, expostas nos planos de desenvolvimento, e desenvolvimento regional, no Brasil, em várias circunstâncias, refletem a sobreposição da agenda econômica capitalista sobre outras possíveis. Destacam-se as grandes agendas nacionais de desenvolvimento desde a década de 1930, com a "corrida para o oeste" de Getúlio Vargas, o Plano de Metas de Juscelino Kubitschek, na década de 1950 e o II Plano Nacional de Desenvolvimento, lançado na década de 1970, pela ditadura militar (Brandão, 2007). Mesmo com a ascensão da política econômica neoliberal da década de 1980, em que o discurso desenvolvimentista de Estado perde força, o que se viu foi o reforço de uma proposta de uso do território por agentes de mercado, alavancada por uma narrativa da globalização, em que as relações no local deveriam se adequar a uma perspectiva de inserção na inevitável rede mundial de relações econômicas ${ }^{2}$ (Brandão, 2007; Santos, 2002).

Certamente, uma das mais fortes tradições de utilização do conceito de território está nas concepções que o entendem como forma jurídico-política. Nessa abordagem, especialmente definida em parte da Geografia Política, território e territorialidade também correspondem a uma expressão geográfica de poder (Cox, 2002). Nessa linha de raciocínio, o conceito de território está relacionado aos fundamentos materiais do Estado. ${ }^{3} 0$ projeto de modernidade civilizacional reforça essa concepção estatal de território, em que a dimensão econômica de poder está incrustada sob forma, ou alimentada pelo discurso em torno, da ideia de desenvolvimento. Furtado (1978) ao analisar o processo histórico de construção do que ele chama de ideologia do desenvolvimento, ressalta a figura do Estado como agente facilitador das formas de acumulação dos agentes privados privilegiados, por meio daquilo que é conhecido como política econômica.

Raffestin (1993) considera o espaço e o tempo como suporte não apenas das relações sociais, mas também como trunfos que se valem para a sustentação ou construção de relações de poder. São mediadores, suporte e recursos dos mecanismos de poder, que se sustentam pela construção histórico-espacial de tecnologias que evidenciam um saber-fazer - uma "verdade", produzida pelas relações de poder, que torna o espaço-tempo, em suas variadas escalas, essencialmente político (Lefebvre, 1991). Desta forma, o território, como uma derivação de uso do espaço, também é demarcado e produzido por relações de poder. Isso traz uma perspectiva política interessante de uso do território, inclusive conceitual. Raffestin (1993) procura evidenciar é que há, no mundo, um choque de forças com relação aos diferentes usos, ou diferentes formas de produção de território. Souza (2007), por exemplo, destaca as distinções de propostas territoriais entre o uso 
formal da cidade durante o dia e o uso informal promovido por prostitutas no período noturno. Martins (1991), por sua vez, discute o contraste entre sociabilidades indígenas amazônicas e a expansão da fronteira agrícola. Em mais um exemplo amazônico, Gonçalves (2001) analisa como o cotidiano das populações extrativistas está vinculado ao de grandes grupos da indústria de cosméticos. Como expõe Costa (2006): o território é uma produção relacional, que envolve os diversos aspectos da vida humana, material e cultural.

A evidência do conflito revela, também, a existência de estratégias. Quando se trata da manifestação espacial de uma estratégia de poder, uma importante contribuição é a de Sack (1986), que se utiliza do conceito de territorialidade. Esse conceito é utilizado para se elaborar uma classificação de área, que faz do território um instrumento utilizado para padronização interna e comparação com territorialidades externas. Trata-se, segundo Costa (2006), de um controle, uma vez que, dentro dessa perspectiva, os indivíduos de um território devem ser considerados como iguais, ou pertencentes à mesma territorialidade. A ideia de Sack (1986) abre caminho para a interpretação de estratégias de produção de território nas mais variadas escalas, desde o nível das relações pessoais, de organização de um bairro, até a formação de blocos políticos internacionais. 0 destaque de Sack, entretanto, é dado para as estratégias estatais de desenvolvimento de uma determinada territorialidade. Assim, foi esboçada a governamentalidade necessária para a aplicação da estratégia de desenvolvimento, o que envolve, antes de qualquer coisa, a classificação da territorialidade por meio da padronização de alguns parâmetros de avaliação (indicadores) estipulados pelo Estado. Cria-se, dessa forma, um ambiente interno para que as ações sociais convirjam para o objetivo único predeterminado. Nesse sentido, territorialidade está intimamente vinculada à ideia de desenvolvimento - ou melhor, ao projeto desenvolvimentista estatal, pretensamente unificador, que, de certa forma, cria barreiras à proposição de projetos alternativos de sociedade.

Essas contribuições apresentadas até aqui deixam claro que território deve ser compreendido como um resultado de relações sociais e que existe uma complexa dinâmica de conflito entre propostas de territorialização, que alimenta um processo contínuo de territorialização-desterritorialização-reterritorialização. Essa dinâmica de conflitos é alimentada por diversas estratégias de produção de território, que, por vezes, podem ser extremamente agressivas e excludentes entre si (Figura 1).

0 propósito de resgate do conceito de territorialismo se dá, justamente, para a análise das estratégias territorialização. $A$ incursão teórica sobre o territorialismo ganha reforço com a construção de autores consagrados da Geografia brasileira. Por exemplo, Castro (2005) ao abordar os conflitos entre Estados Nacionais, considerados centrais na geopolítica moderna, aborda o territorialismo como estratégia em uma dinâmica de disputas pela delimitação de fronteiras entre os países. Nos argumentos propostos por Castro (2005), a competição internacional por controle de fronteiras está intimamente vinculada às condições materiais da circulação no sistema capitalista. Nesse processo, o Estado assume papel estratégico na produção do território, seja como área geopoliticamente delimitada (escala do nacional) seja como rede (transações de 
Figura 1 - Dinâmica de territorialização-desterritorialização-reterritorialização

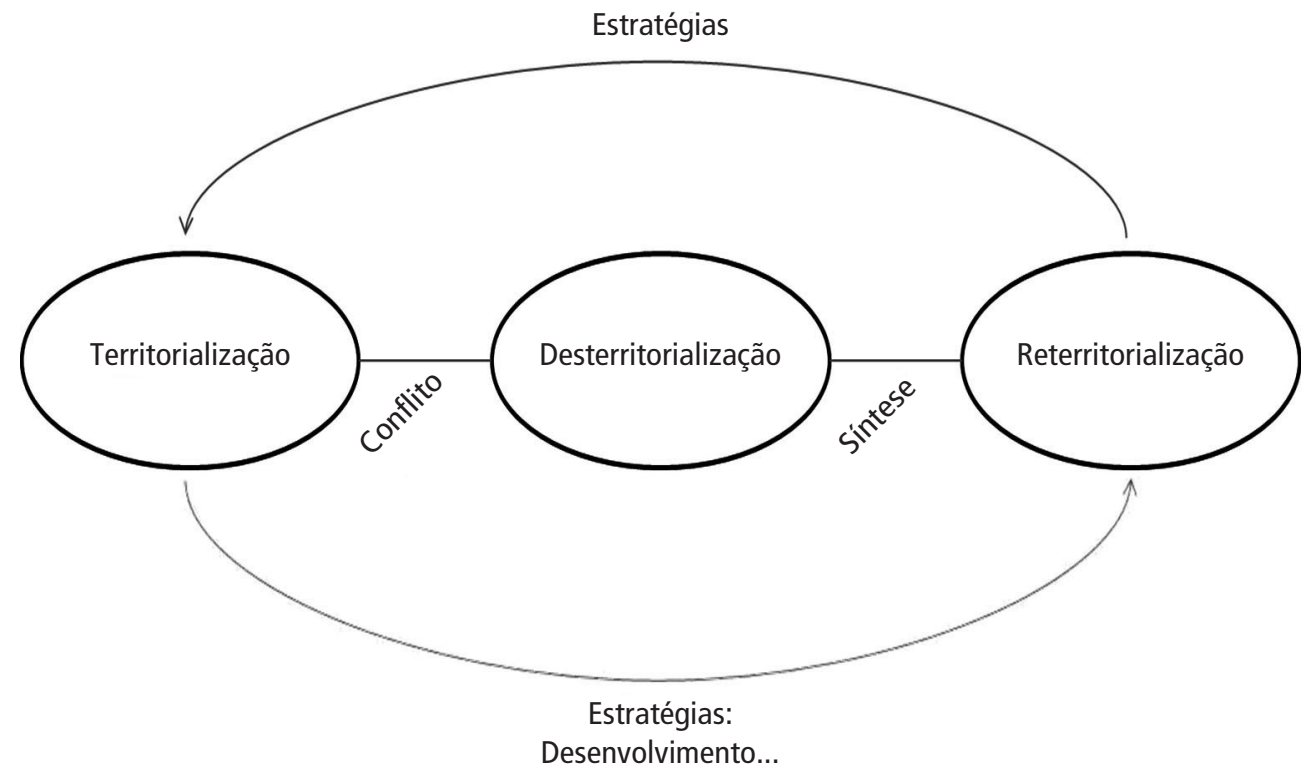

valores em escala global). A autora defende a relevância desse debate na atualidade, apesar dos avanços tecnológicos e das novas estratégias decorrentes do processo de globalização. Isso pode ser observado, pela ascensão, no âmbito do discurso neoliberal, das estratégias de desenvolvimento local e regional, que mais significam abertura dessas escalas para o circuito mercadológico capitalista, porém, agora, com formas próprias de governança, diferentes do Estado Nacional (Brandão, 2007). Castro (2005) também procura demonstrar que existe uma dualidade na atuação do Estado na produção do território. Trata-se de uma dualidade escalar: de um lado o Estado e suas relações com o ambiente geopolítico externo - que diz respeito às disputas com outros Estados-nacionais, seja pelo controle de fluxos econômicos, seja para o exercício de influência política; de outro, a relação do Estado com a dinâmica interna - em que se apresentam as estratégias de controle social, que nesse caso quer dizer controle das práticas políticas que se desenham e produzem espaço. A dualidade percebida na atuação do Estado, em duas escalas destacadas, por estarem interconectadas, favorece a compreensão de que ele cumpre o papel de articulador dos fluxos de reprodução do valor e de ator tático de uma governamentalidade social que sustenta a pretensa naturalidade das práticas hegemônicas de poder vigentes na narrativa capitalista/desenvolvimentista. 0 territorialismo, representado pela ação social do Estado, conforme aponta Castro (2005), faz parte de um processo amplo de produção de território sob a égide da racionalidade de mercado. 
Costa (2006) dá um importante uso para a noção de territorialismo, quando apresenta sua natureza cultural, cujo foco é dado às iniciativas que ele caracteriza como etnicização da vida social (Costa, 2006). Nesses casos, a ideia de territorialismo também não foge à ação política. Na verdade, ele mostra que alguns grupos recorrem a características tipicamente culturais como estratégia de política de manutenção de uma sociabilidade, em contraponto a uma dinâmica que o fragiliza. Costa (2006) também analisa a questão utilizando-se da tese de "choque de civilizações", proposta por Huntington (1997). As identidades culturais seriam motores da dinâmica de conflitos, bem como de algumas coesões, como foi possível perceber no período após Guerra Fria, em um movimento de territorialização em torno das civilizações. Costa (2006) ainda critica o caráter simplista da interpretação da territorialidade das civilizações, embora destaque que essa abordagem cultural/territorialista abre campo para a investigação de importantes movimentos sociais, nas mais diversas escalas, inclusive na escala das redes, como nas diásporas de imigrantes.

Souza (2007), ao discutir a pertinência do uso do conceito de territorialidade como uma representação de "controle territorial", defende o uso da noção de territorialismo, como estratégia de dominação do espaço.

Para qualificar a noção de territorialismo, não se pode deixar de lado a definição de Brunet (1993) e a consequente interpretação que Costa (2006) faz acerca de seu conteúdo: um conceito mau visto, ligado à ideia de terrorismo e exclusão. A proposta que se defende nesse trabalho é de que as políticas de desenvolvimento, no que se refere à produção de território, podem ser analisadas como conteúdo estratégico de sobreposição lógica das formas de sociabilidade capitalista. Pode-se, portanto, considerar que o desenvolvimento, como ideia e discurso, faz parte de uma estratégia territorialista de produção do espaço vinculada às formas de reprodução capitalistas. Trata-se de um territorialismo capitalista, que se manifesta pelo exercício de poder que procura tornar "natural" determinado tipo de prática social.

\section{Territorialismo e desenvolvimento regional: as promessas do Plano Amazônia Sustentável}

A análise de uma política específica de governo permite observar a lógica territorialista da reprodução capitalista, mesmo em um governo que surge em meio a um discurso, pelo menos aparentemente questionador. Também é possível perceber como esse discurso se reflete nas projeções político-governamentais de produção de território(s), de acordo com o pensamento hegemônico na contemporaneidade. A escolha da política analisada não foi dada ao acaso, pois se trata do lugar institucional em que o governo desse período alocou conceitualmente boa parte da discussão sobre produção de território(s). Trata-se da Política Nacional de Desenvolvimento Regional (PNDR), assumida formalmente desde 2007 (Brasil, 2007) e coordenada Pelo Ministério da Integração Nacional (MIN).

Pode-se dizer que o maior avanço da PNDR foi a institucionalização, ainda que de forma embrionária, de espaços de diálogo com 
a população. Em suas diversas áreas de atuação, as ações geralmente foram desenvolvidas com base em uma abordagem participativa. Por outro lado, percebe-se que dentro dessa abordagem há a combinação ambígua entre um sentido educador (disciplinador) e um sentido de verificação das reais necessidades e entendimento das formas de reprodução social das diferentes territorialidades brasileiras. Analisar o processo participativo, presente nos planos de desenvolvimento regional vinculados à PNDR, nos permite identificar as diferentes estratégias de produção de território e a síntese que leva à reterritorialização, portanto, com a revelação de estratégia hegemônica de produção de território. A verificação desse movimento contraditório da abordagem participativa pode ser investigada nos Planos de Desenvolvimento Regional elaborados durante a década de 2000. Os principais: "Plano Estratégico de Desenvolvimento Sustentável do Semi-Árido" (PDSA) (Brasil. Ministério da Integração Nacional, 2005); "Plano Estratégico de Desenvolvimento do Centro-Oeste (2007-2020)" (Brasil. Ministério da Integração Nacional, 2007); e "Plano Amazônia Sustentável" (Brasil. Presidência da República, 2008).

0 caso do "Plano Amazônia Sustentável" é um exemplo marcante dos contrastes presentes na produção do território. De um lado populações seculares, que têm a floresta como elemento central de sua reprodução; de outro, as incursões dos diversos setores capitalistas sobre os recursos naturais da Amazônia, bem como sobre os "povos da floresta" com o intuito de incorporação de suas práticas ao circuito geral de acumulação capitalista. A estrutura de organização do plano e seu processo participativo colocam importante ênfase sobre as condições dos diversos povos amazônicos. Todavia, apesar do esforço de compreensão das diferentes dinâmicas de reprodução social, 0 núcleo central ainda se concentra na perspectiva de inclusão da região nos circuitos globalizados da economia capitalista. De modo geral, esse plano representa o registro formal de uma série de conflitos relacionados à produção do território amazônico. Representa uma tentativa de produção de "consensos", mesmo lidando com questões em que o acordo é bastante improvável. De um lado, o reconhecimento das diversidades amazônicas (Quadro 1). De outro lado, verifica-se o estímulo ao enquadramento competitivo dos recursos amazônicos ao circuito cosmopolita da economia (Quadro 2).

Com esse conjunto de diretrizes o que se percebe, em certa medida, é o esforço em favorecer as tradicionais frações do capital brasileiro, historicamente especulativo e mercantil (Brandão, 2007). Por uma terceira via, observam-se as diretrizes que são a essência do esforço conciliatório, por incorporarem o discurso político-ambiental nas iniciativas de inclusão mercadológica competitiva (Quadro 3). 


\section{Quadro 1}

\section{Diretrizes para preservação das diversidades amazônicas}

Valorização da diversidade sociocultural e ambiental.

Ampliação da presença do Estado para estabelecimento de maior governabilidade no que diz respeito à ocupação e ao uso dos recursos naturais, às transformações socioprodutivas e garantia dos direitos das populações tradicionais.

Segurança quanto ao direito de reprodução social das populações tradicionais.

Combate ao desmatamento.

Proteção da floresta e demais recursos naturais.

Estabelecimento de mecanismos voltados ao consumo local e regional de produtos oriundos de movimentos de economia popular e solidária.

Fonte: Brasil. Presidência da República (2008).

\section{Quadro 2}

\section{Diretrizes para inserção da economia amazônica ao circuito competitivo capitalista}

Estímulo ao adensamento da cadeia produtiva do agronegócio para atendimento de mercados externos.

Consolidação de iniciativas como a do polo industrial da zona franca de Manaus.

Estímulo à formação de novos polos industriais vinculados à exploração de recursos naturais, nesse caso, os setores gás-químico, cloro-químico, mineração e de materiais de transporte fluvial.

Fonte: Brasil. Presidência da República (2008).

\section{Quadro 3}

\section{Diretrizes para conciliação de territorialidades}

Combate ao desmatamento ilegal e ao uso do solo em padrão extensivo.

Recuperação florestal.

Estímulo ao uso múltiplo da floresta, em bases sustentáveis, principalmente, com aplicação de conhecimento técnico-científico e com a promoção de capacitação das populações usuárias.

Incentivo aos assentamentos rurais de base sustentável.

Revisão do marco regulatório sanitário e fiscal para as cadeias produtivas de fitoterápicos, para estímulo ao uso sustentável da biodiversidade.

Fonte: Brasil. Presidência da República (2008). 
A história da Amazônia revela a dinâmica da formação da territorialidade de povos que, secularmente, encontraram na floresta sua forma de sobrevivência e reprodução social. Indígenas, negros-quilombolas, caboclos, camponeses ribeirinhos e migrantes vindos de diversas regiões, principalmente pobres originários do Nordeste brasileiro. Contudo, foi a partir da encarnação da face política do discurso ecológico, em meados da década de 1970, que a menção constante à necessidade de fortalecimento e incentivo às práticas que estejam em equilíbrio com os biomas amazônicos e, também, com suas populações, se torna comum e extrapola, sob a forma de discurso, para além das fronteiras amazônicas. Claramente se nota a criticidade deste discurso, que se constrói como contraponto à forma com que historicamente se estabeleceram as relações de produção hegemônicas no espaço amazônico.

Costa (2007) demonstra a força dos setores chamados de conservadores ou convencionais perante a economia regional amazônica. 0 principal deles, o agronegócio tradicional em bases extensivas (intensivas em terra) que, apesar das possibilidades tecnológicas disponíveis, em virtude das possibilidades/facilidades de expansão ao longo das terras amazônicas, segue em um quadro de modernização conservadora e devastadora, que marca o território amazônico (Costa, 2007). Podem-se incluir no bojo os projetos do setor de mineração, já tradicionais e em constante expansão na região, assim como os grandes projetos hidroelétricos, historicamente capitaneados pelo Governo brasileiro, a exemplo do que acontece atualmente com o Projeto Belo Monte, em Altamira, no Pará. Martins (1991) bem exemplifica o poder devastador que tais projetos exercem sobre as territorialidades dos povos da floresta ao analisar os pressupostos desses projetos: remoção, aniquilamento, integração ou assimilação das populações indígenas e demais povos da floresta que se apresentem como entraves ao projeto desenvolvimentista.

Essas estratégias e princípios permanecem vigentes, mesmo em debates avançados como o do PAS. É claro o tom dramático que se estabelece decorrente do antigo/atual modelo de desenvolvimento, que tem como fundamento a transformação da Amazônia em um território guiado pelos princípios do pensamento competitivo, como alerta Gonçalves (2001). Apesar da crescente mobilização por lutas sociais na história da Amazônia e seus efeitos na diminuição da sujeição do homem do campo às imposições da modernização conservadora, essas populações têm sido cada vez mais "periferizadas" em meio a esse movimento de integração. As propostas alternativas, que procuram impregnar uma visão político-ecológica nas atividades de inserção da Amazônia no circuito competitivo não rompem com a ordem de conhecimento do projeto desenvolvimentista. Costa (2007), por exemplo, descreve o que chama de "outros sistemas produtivos da economia amazônica", que têm como premissa um modelo de desenvolvimento "alternativo" que preconiza uma

[...] desejável combinação entre proteção dos ecossistemas relevantes, o uso racional dos recursos naturais [...], a adoção de sistemas rurais de produção que não impliquem 0 acelerado processo atual de desmatamento e, sobretudo, a introdução ou o fortalecimento de sistemas produtivos que sejam capazes, ao mesmo tempo, de promover a elevação dos padrões de vida das suas populações. (Costa, 2007, p. 86) 
No centro desse debate estariam os bioprodutos: valores-de-uso formulados pelos recursos florestais em bases técnico-científicas avançadas que se transformam em mercadoria por meio das relações do ecobusiness. Esse tipo de mercadoria se desenvolve em mercados como o de produtos de saúde (fitoterápicos, conforme apontado pelo PAS), cosméticos e, também, o agronegócio (Costa, 2007). Costa alerta para o potencial econômico da descoberta de novos "biomateriais" através da pesquisa de plantas medicinais e toxinas animais, algo bastante pertinente, principalmente pela apropriação do conhecimento das populações que há séculos lidam com os recursos da floresta e que nos últimos anos têm sido refinados, do ponto de vista mercadológico, por pesquisas elaboradas em centros especializados e pesquisas biotecnológicas (Gonçalves, 2001). 0 bioproduto seria a chave para a integração entre as atividades de subsistência secularmente desenvolvidas nas florestas e atores econômicos de natureza, escala e posições diversas.

Pode-se verificar, pelas estratégias apresentadas como supostamente "alternativas", que se trata do fortalecimento de setores econômicos, sujeitos às contradições do amplo circuito de reprodução capitalista. A proposta se encaminha em dois sentidos: 1) enquadramento das atividades de povos que durante longo tempo exercem atividades extrativistas e camponesas em um circuito de mercado, proporcionando que o produto do trabalho desses povos se torne mercadoria, mesmo que não seja resultado de um processo capitalista de produção (Martins, 1993); 2) apropriação do conhecimento desenvolvido pelas culturas locais, conforme expõe Gonçalves (2001), em favor de inovações tecnológicas que permitam o desenvolvimento de novas mercadorias e, por consequência, de novos mercados. Antes, é preciso lembrar que esse movimento não é novo e se faz prática recorrente na história da Amazônia. Cita-se, como exemplo, a apropriação do conhecimento indígena sobre as possibilidades do látex, ainda em meados do século XIX (Gonçalves, 2001).

Parece razoável crer no potencial de tais atividades em ampliar a qualidade de vida das populações que dependem da floresta para sua reprodução. Todavia, nesse âmbito, não se constroem relações isentas de críticas. Existem vários pontos em que se pode questionar, como a questão do direito ao conhecimento produzido, que atualmente, na sociedade moderna, discutimos em termos de patentes. Em uma crítica mais radical, pode-se questionar a perspectiva de ganhos sobre qualquer conhecimento, que derivados de relações sociais perante a natureza, em essência, seriam coletivos (Gonçalves, 2001).

A tendência decorrente do projeto "alternativo" de desenvolvimento é a prevalência de uma produção do território que está vinculado aos parâmetros da sociedade ocidental capitalista, a ideologia do desenvolvimento, portanto com todas suas contradições inerentes (Furtado, 1978; Santos, 1996). Nesse aspecto, parece que se está diante de uma regra que coloca como premissa a competitividade. Mesmo as relações de produção consideradas "alternativas", como o processo que envolve os bioprodutos, parecem estar subordinadas a essa estratégia de produção territorial sustentada pelas políticas no âmbito do Estado. Trata-se de um territorialismo capitalista, em que as forças competitivas de mercado são colocadas como alternativa única 
de sociabilidade e que se consolidam de forma avassaladora e intolerante.

\section{Considerações finais}

Esse trabalho representa um esforço de compreensão acerca das estratégias políticas de produção de território. Há, nesse aspecto, a necessidade de se investigar mais a fundo 0 conteúdo político do modelo socioespacial hegemônico em nosso tempo, incluindo a dimensão política da proposta de desenvolvimento capitalista e sua produção de território. 0 conceito de territorialismo é útil a esse propósito, uma vez que revela o conteúdo intolerante das formas sociais capitalistas com relação àquelas radicalmente diferentes. Ajuda a compreender que no ambiente das políticas de desenvolvimento construídas pelo Estado, apesar das provocações dos diferentes grupos e atores sociais, em favor de suas formas de produção de território, vigora, na essência dos planos e projetos, a lógica dos agentes que possuem interesses nas formas de acumulação do circuito amplo de reprodução capitalista.

No de ano de 2012, a PNDR passou por um processo de revisão por meio de conferências (estaduais, macrorregionais e nacional) de desenvolvimento regional, que contou com a participação de representações da sociedade civil. A princípio, parece uma tentativa de verificação social dos resultados dos primeiros anos da Política e um mecanismo de fortalecimento de seus quadros institucionais do Ministério da Integração Nacional perante a estrutura organizacional do Governo Federal. Foram apresentadas, pelo próprio Governo, críticas à implementação da PNDR em seus primeiros anos, até 2010. As principais dizem respeito à baixa capacidade de financiamento da Política e as suas incapacidades de articulação federativa e intersetorial, no âmbito do próprio Governo Federal (Brasil. Ministério da Integração Nacional, 2012).

Em março do ano de 2013, o processo conferencial proposto pelo MIN culmina na I Conferência Nacional de Desenvolvimento Regional (ICNDR). Nesse espaço de debate, foram elaborados os princípios e diretrizes regentes de uma nova fase da PNDR. A análise dos princípios e diretrizes mostra que, de fato, a noção de desenvolvimento funciona como um eficiente formador de "consensos". Ela está impregnada no saber social e orienta as formas de se pensar a sociedade. Apesar disto, verifica-se uma série de expressões conflituosas que permearam o debate desenvolvimentista na ICNDR, o que fica marcado nas fortes reivindicações em favor: do respeito às diversidades regionais; dos direitos das populações tradicionais; da garantia dos direitos fundamentais, previstos na Constituição Federal de 1988; da ampliação dos mecanismos de participação social; e de uma articulação federativa entre os três níveis (municípios, estados e União), baseada em relações de cooperação e solidariedade. Reivindicações contrárias a um modelo de desenvolvimento considerado excludente e concentrador (Brasil. Ministério da Integração Nacional, 2013a; 2013b). Algo marcante que surgiu da ICNDR foi a proposta de criação de um Sistema Nacional de Desenvolvimento Regional, "como instrumento de planejamento, monitoramento, regulação e avaliação das políticas [...]" (Brasil. Ministério da Integração Nacional, 2013b). A ideia 
construída foi a de que esse Sistema funcione por meio de intensa participação social, com poder deliberativo.

Verifica-se, ainda, o embrião de uma proposta contestadora mais radical. Surge nos princípios e nas diretrizes da ICNDR a ideia de um planejamento de bases solidárias, que se propõe a romper com a lógica fragmentadora de produção de territórios competidores (Brasil. Ministério da Integração Nacional, 2013b). A verificação desse embrião de contestação em favor de um maior empoderamento social do processo de tomada de decisões para a produção de território permite vislumbrar a esperança de algo realmente novo, capaz de captar questões da realidade que apontem para um momento de transição (Freire, 1969).

A reivindicação, mais do que isso, a efetiva apropriação dos espaços institucionais de decisão, indutores da produção do território, incrustrados nos aparelhos de Estado, alertam para esforço desempenhado em favor de outras narrativas de produção de território. Esses esforços não apontam, simplesmente, para a necessidade de incorporação de sua perspectiva em um esforço adaptativo com relação aos circuitos capitalistas, capitaneado pelo Estado. Aponta, em verdade, a necessidade de tolerância política para com seu projeto. A perspectiva estratégica incrustada nesses esforços tem como fundamento a crítica: o apontamento do caráter contraditório dos discursos em torno da ideia de desenvolvimento. Portanto, mesmo que, aparentemente, os espaços participativos aparentem estar preenchidos pelas ideias desenvolvimentistas, próprias da reprodução capitalista, o diferente, o diferencial tem aflorado (Lefebvre, 1991). De modo que, a partir desses espaços de participação, surgidos em ambientes como o da PNDR, é possível que as populações passem a entender o seu papel de sujeito que, coletivamente, se apropria de seu potencial criativo e produza territorialidades diferenciais.

\section{Weslley Cantelmo}

Secretaria de Estado de Desenvolvimento Regional, Política Urbana e Gestão Metropolitana, Superintendência de Planejamento e Apoio ao Desenvolvimento Regional. Belo Horizonte/MG, Brasil. weslleycantelmo@yahoo.com.br

\section{Carlos Lobo}

Universidade Federal de Minas Gerais, Instituto de Geociências, Departamento de Geografia. Belo Horizonte/MG, Brasil.

carlosfflobo@gmail.com

\section{Ricardo Alexandrino Garcia}

Universidade Federal de Minas Gerais, Instituto de Geociências, Departamento de Geografia. Belo Horizonte/MG, Brasil.

alexandrinogarcia@gmail.com 


\section{Notas}

(1) No senso comum a noção de território frequentemente remete a definição de áreas, ou zonas, sobre influência de uma lógica, geralmente, imperativa, restritiva e fechada em si. Não raro, aponta vários exemplos possíveis de serem identificados no cotidiano, que incluem desde o território conquistado em um jogo juvenil, em que a guerra se faz no tabuleiro, até o discurso de um presidente ao enfatizar a necessidade de se proteger o território nacional. Fala-se, ainda, em território de um grupo, de uma empresa, por exemplo, em uma clara referência à propriedade privada, quase sempre relacionados à perspectiva de zona delimitada.

(2) Vale ressaltar, que mesmo com a perda de força do discurso estatal de desenvolvimento, o Estado segue como ator primordial na proposta neoliberal de uso/produção do território. As privatizações e a redução das participações estatais diretas em serviços públicos, dos mais diversos tipos, são consequência de uma crise da capacidade do Estado em sustentar a reprodução das mais diversas formas de capital no território (Brandão, 2007; Cano, 2002; Harvey, 1982; Tavares, 1999). Do mesmo modo, fortaleceram-se os discursos locais, no Brasil, representado pelas causas municipalistas, que revelam o protagonismo de elites locais/regionais na proposição dos usos do território.

(3) Nessa discussão Friedrich Ratzel é uma referência clássica. Na acepção ratzeliana, o território é espaço sob a égide do domínio humano. É uma área sobre controle político, que coresponde ao controle do Estado (Moraes, 2000; Costa, 2006). Para Ratzel, como demonstram Raffestin (1993) e Costa (2006), o território pode ser definido como o espaço vital - espaço ótimo de reprodução de um grupo ou de uma civilização, que oferece a esse coletivo, conforme suas dimensões e necessidades, as condições materiais (ou o "substrato material") e a dimensão política necessária como representação da figura do Estado.

\section{Referências}

ARRIGHI, G. (1996). O longo século XX: dinheiro, poder e as origens de nosso tempo. São Paulo, Fundação Editora da Unesp.

BRANDÃO, C. (2007). Território e desenvolvimento: as múltiplas escalas entre o local e o global. Campinas, Editora da Unicamp.

BRASIL (2005). Ministério da Integração Nacional. Plano estratégico de desenvolvimento sustentável do semiárido (versão para discussão). Brasília. Disponível em: http://www.mi.gov.br/c/ document_library/get_file?uuid=347a66e5-2e91-49b7-9bd5-5762d4ae3e02\&groupld=24915. Acesso em: 25 maio 2014.

(2007). Ministério da Integração Nacional. Plano estratégico de desenvolvimento do Centro-Oeste. Brasília. Disponível em: http://www.sudeco.gov.br/c/document_library/get_ file?uuid=0bad5e63-814d-4a4f-acdb-52d23b6b8f80\&groupld=14019. Acesso em: 25 maio 2014. 
BRASIL (2007). Decreto no 6.047, de 22 de fevereiro. Institui a Política Nacional de Desenvolvimento Regional e dá outras providências. Brasília: Presidência da República. Disponível em: http://www. planalto.gov.br/ccivil_03/_ato2007-2010/2007/decreto/D6047.htm. Acesso em: 25 maio 2014.

(2008). Presidência da República. Plano Amazônia Sustentável: diretrizes para o desenvolvimento sustentável da Amazônia Brasileira. Brasília. Disponível em: http://www.mma.gov.br/mwginternal/de5fs23hu73ds/progress?id=SfXA7soUK8. Acesso em: 25 maio 2014.

(2012). Ministério da Integração Nacional. I Conferência Nacional de Desenvolvimento Regional: documento de referência. Secretaria de Desenvolvimento Regional. Disponível em: http://www.mi.gov.br/c/document_library/get_file?uuid=54bce099-503a-4076-8613d90dd6107c79\&groupld=10157. Acesso em: 25 maio 2014.

(2013a). Ministério da Integração Nacional. I Conferência Nacional de Desenvolvimento Regional (ICNDR): Relatório final. Priorização da etapa nacional da ICNDR. Princípios. Brasília. Disponível em: http://www.integracao.gov.br/c/document_library/get_file?uuid=881965add8d2-46c7-ac03-d82ea675f97c\&groupld=10157. Acesso em: 25 maio 2014.

(2013b). Ministério da Integração Nacional. I Conferência Nacional de Desenvolvimento Regional (ICNDR): Relatório final. Priorização da etapa nacional da ICNDR. Diretrizes. Brasília. Disponível em: http://www.integracao.gov.br/c/document_library/get_file?uuid=cc53652021e6-4697-bffc-4954340ae883\&groupld=10157. Acesso em: 25 maio 2014.

BRUNET, R. et al. (1993). Les mots de la géographie: dictionnaire critique. Montpellier/Paris, Reclus/ La Documentation Française.

CANO, W. (2002). Ensaios sobre a formação econômica regional do Brasil. Campinas, Editora do IEUnicamp.

CASTRO, I. E. de (2005). Geografia e política: território, escala de análise e instituições. Rio de Janeiro, Bertrand Brasil.

COSTA, R. H. da (2006). O mito da desterritorialização: do fim dos territórios à multiterritorialidade. Rio de Janeiro, Bertrand Brasil.

COSTA, W. M. da (2007). "Tendências recentes na Amazônia: os sistemas produtivos recentes". In: COSTA, W. M.; BECKER, B. K. e ALVES, D. S. (orgs.). Dimensões humanas da biosfera-atmosfera na Amazônia. São Paulo, Edusp.

COX, K. (2002). Political gography: territory, state, and society. Malden, Massachusetts, Blackwell Publishers.

FREIRE, P. (1969). Educação como prática da liberdade. Rio de Janeiro, Paz e Terra.

FURTADO, C. (1978). Criatividade e dependência na civilização industrial. Rio de Janeiro, Paz e Terra.

GONÇALVES, C. W. P. (2001). Amazônia, Amazônias. São Paulo, Contexto.

HARVEY, D. (1982). Limits to capital. Oxford, Basil Blackwell.

HISSA, C. (2009). "Territórios de diálogos possíveis". In: RIBEIRO, M. T. F. e MILANI, C. R. S. (orgs.). Compreendendo a complexidade socioespacial contemporâneo: o território como categoria de diálogo interdisciplinar. Salvador, EDUFBA.

HUNTINGTON, S. P. (1997). O choque de civilizações e a recomposição da ordem mundial. Rio de Janeiro, Objetiva. 
LEFEBVRE, H. (1991). The production of the space. Oxford, Blackwell Publishers.

MARTINS, J. de S. (1991). "A chegada do estranho (Notas e reflexões sobre o impacto dos grandes projetos econômicos nas populações indígenas e camponesas da Amazônia)". Prefácio. In: HÉBETTE, J. (org.). O cerco está se fechando: o impacto do grande capital na Amazônia. Rio de Janeiro, Fase.

(1993). A chegada do estranho. São Paulo, Hucitec.

MORAES, A. C. R. (2000). Bases da formação territorial do Brasil: o território colonial brasileiro no "longo" século XVI. São Paulo, Hucitec.

RAFFESTIN, C. (1993). Por uma geografia do poder. São Paulo, Ática.

SACK, R. (1986). Human territoriality: its theory and history. Cambridge, Cambridge University Press.

SANTOS, M. (1996). A natureza do espaço: técnica e tempo. Razão e emoção. São Paulo, Hucitec. (2000). O papel ativo da geografia. Revista Território. Rio de Janeiro, n. 9, pp. 103-109. (2002). Por uma nova geografa: da crítica da geografia a uma geografia crítica. São Paulo, Edusp.

(2005). Da totalidade ao lugar. São Paulo, Edusp.

SOUZA, M. de (2007). “O território: sobre o espaço, poder, autonomia e desenvolvimento”. In: CASTRO et al. (orgs.). Geografia: conceitos e temas. Rio de Janeiro, Bertrand Brasil.

TAVARES, M. da C. (1999). “Império, território e dinheiro”. In: FIORI, J. L. (org.). Estados e moedas no desenvolvimento das nações. Petrópolis, Vozes.

Texto recebido em 22/mar/2015 Texto aprovado em 29/jun/2015 